\title{
Old Acid, New Chemistry. Negative Metal Anions Generated from Alkali Metal Oxalates and Others
}

\author{
Sharon Curtis, Justin Renaud, John L. Holmes, and Paul M. Mayer \\ Department of Chemistry, University of Ottawa, Ottawa, Ontario, Canada
}

A brief search in Sci Finder for oxalic acid and oxalates will reward the researcher with a staggering 129,280 hits. However, the generation of alkali metal and silver anions via collision-induced dissociation of the metal oxalate anion has not been previously been reported, though Tian and coworkers recently investigated the dissociation of lithium oxalate [18]. The exothermic decomposition of alkali metal oxalate anion to carbon dioxide in the collision cell of a triple quadrupole mass spectrometer leaves no place for the electron to reside, resulting in a double electron-transfer reaction to produce an alkali metal anion. This reaction is facilitated by the negative electron affinity of carbon dioxide and, as such, the authors believe that metal oxalates are potentially unique in this respect. The observed dissociation reactions for collision with argon gas $\left(1.7-1.8 \times 10^{-3} \mathrm{mbar}\right)$ for oxalic acid and various alkali metal oxalates are discussed and summarized. Silver oxalate is also included to demonstrate the propensity of this system to generate transition-metal anions, as well. (J Am Soc Mass Spectrom 2010, 21, 1944-1946) (c 2010 American Society for Mass Spectrometry

$\mathrm{T}$ The chemical concept of metals producing positive ions (cations) and non-metals negative ions (anions) is a fundamental precept taught as early as in high school and reinforced throughout a person's university career. However, under certain conditions, metal anions can be created and, as such, their electron affinities are well characterized and calculated both experimentally and theoretically [1]. In solution, alkali metal anions (except lithium) in 'supra molecule complexes' have been prepared in THF and crown ethers. These characteristically blue solutions are now fabricated to control the amount of metal ions, including metal anions. Such solutions have been extensively studied for use in organic synthesis and elucidation of charge-transfer to solvent dynamics (CTTS) [2-9]. In the gas phase, a beam of positively charged alkali cations created from metal vapor can undergo double electron capture to generate a low density negative ion beam [10]. Other means of negative ion generation include discharge and sputter ion sources, namely $\mathrm{Cs}^{+}$ions with a suitable metal cathode [11]. Studies in ion traps utilize dissociative electron attachment to create metal anions [12]. Thus, metal anions are created only via complex experimental procedures or specific experimental apparatus. This paper outlines a method for the production of metal anions requiring a simple oxalate

Address reprint requests to Professor P. M. Mayer, Department of Chemistry, University of Ottawa, 10 Marie Curie, Ottawa, ON K1N 6N5, Canada. E-mail: pmmayer@uottawa.ca salt solution and a commercially available triple quadrupole mass spectrometer.

Oxalic acid is one of the oldest known acids, first isolated from wood sorrel (Oxalis acetosella). It is often found as salt oxalates in many biological systems; particular well known is calcium oxalate found in rhubarb root, known for both its medicinal properties and as a potential poison. Ammonium oxalate is found in guano and there is evidence for the sodium and potassium salts present in soil. Oxalic acid can be produced in the lab by oxidation of sugar using nitric acid in the presence of catalytic vanadium pentoxide. Alternatively, it can be readily purchased as the dehydrate or anhydrate, which it forms readily with one or two water molecules [13]. Only the alkali metal salts of oxalic acid are soluble. The affinity for oxalic acid to form insoluble metal complexes is particularly evident in the precipitation of calcium oxalate within the kidney, to produce kidney stones. The oxalate anion is an excellent bidentate ligand for metal complexes producing five membered rings of which potassium ferrioxalate is a good example [14]. In the gas phase, metal oxalate clusters can be readily generated and detected with both negative and positive electrospray mass spectrometry [15-17]. In 2008, Tian and coworkers generated the lithium oxalate anion and reported the loss of $\mathrm{CO}_{2}$ and $\mathrm{CO}$ by CID mass spectrometry, producing the strongest base known to date, $\mathrm{LiO}^{-}[18]$.

The decomposition of oxalic acid and various oxalates has been studied both experimentally and theoretically [19]. Oxalic acid has been noted to decompose 


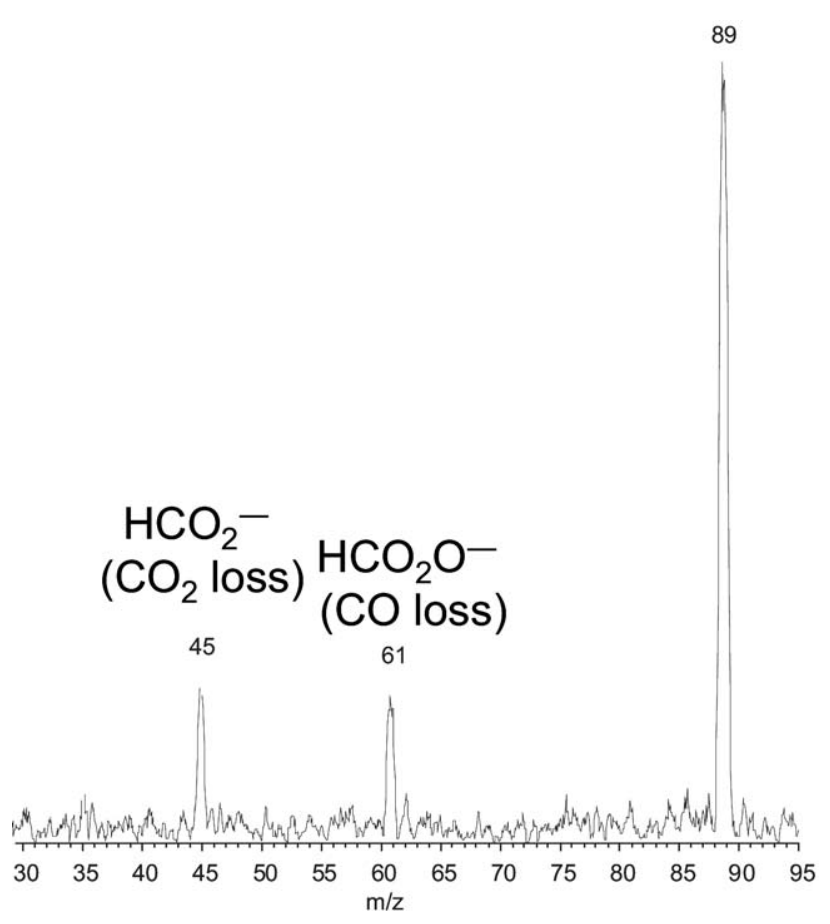

Figure 1. CID spectrum of oxalic acid anion, $\mathrm{HOOCCOO}^{-}(\mathrm{m} / \mathrm{z}$ 89). Laboratory frame collision energy $=8 \mathrm{eV}$ (center of mass collision energy, Ecom $=2.48 \mathrm{eV}$ ).

to carbon dioxide, carbon monoxide, and water [13, 20-23], while the metal oxalates primarily produce metal oxide on decomposition. Silver oxalate decomposes explosively [24].

In most ionic salt solutions or reaction sequences, the electron affinity of the non-metal is so much greater than the metal that the electron always resides with the non-metal. Though metals (transition) are known for their catalytic reaction capabilities, the exact nature of the electron movement is often ambiguous, involving metal-carbon bond strengths and free radical reaction mechanisms [25]. However, when the non-metal is carbon dioxide, which has a negative electron affinity, the electron cannot transfer to the non-metal and must reside with the metal. The collision-induced dissociation of metal oxalate anions in a Micromass Quattro-LC triple quadrupole mass spectrometer via electrospray of the salt solution is an example of this and can therefore

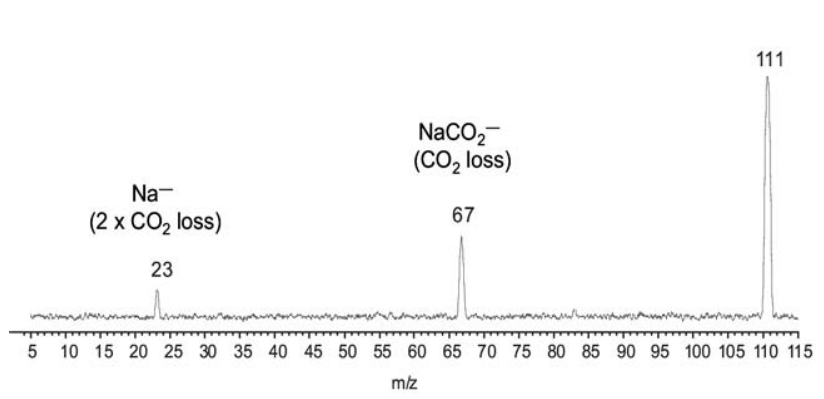

Figure 2. CID spectrum of the sodium oxalate anion, NaOOC$\mathrm{COO}^{-}(\mathrm{m} / \mathrm{z}$ 111). Laboratory frame collision energy $=10 \mathrm{eV}($ Ecom $=$ $2.65 \mathrm{eV})$.

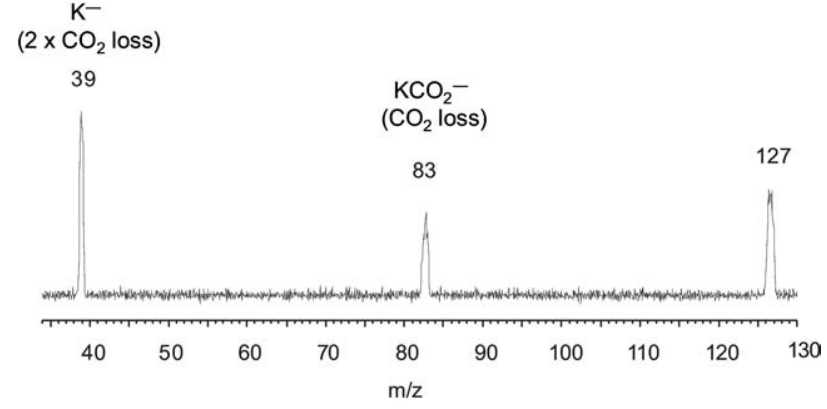

Figure 3. CID mass spectrum of potassium oxalate anion, $\mathrm{KOOCCOO}^{-}(\mathrm{m} / \mathrm{z}$ 127). Laboratory frame collision energy $=10 \mathrm{eV}$ $(\mathrm{Ecom}=2.40 \mathrm{eV})$.

be used to generate metal anions of alkali metals and others.

\section{Results and Discussion}

The observed dissociation reactions on collision with argon gas (1.7-1.8 $\times 10^{-3}$ mbar) for oxalic acid, alkali metal, and silver oxalates anions are shown below.

Oxalic acid (Figure 1) and lithium oxalate [18] anions readily decompose by loss of carbon dioxide to produce a stable hydrogen (lithium) carbon dioxide complex, respectively. A secondary decay channel for loss of carbon monoxide is seen with oxalic acid and lithium oxalate and produces an $\mathrm{MCO}_{2} \mathrm{O}^{-}$ion; it is not seen with the other metal oxalates. There is no evidence for $\mathrm{H}^{-}$or lithium anions similar to the condense phase results previously discussed [4,5]. All peak assignments were confirmed with doubly ${ }^{13} \mathrm{C}$-labeled oxalic acid.

The alkali metal oxalate CID mass spectra in Figures 2 and 3, and that for silver oxalate (Figure 4) all demonstrate metal anions and no $\mathrm{CO}$ fragmentation pathway.

The propensity for the metal oxalate anions to decompose exothermically is governed by an interplay of ion size, electron affinity, and metal charge [21]. In most instances, the low electron affinities of the alkali metals would result in electron-transfer to the non-metal counterpart of the complex. The uniqueness of the metal

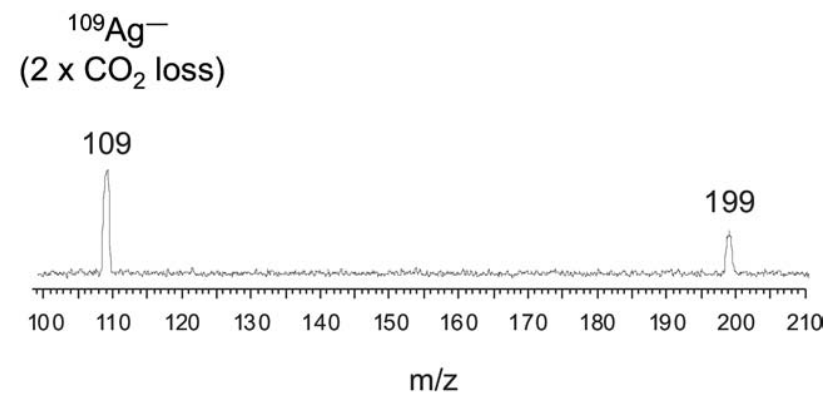

Figure 4. CID mass spectrum of silver oxalate anion, $\mathrm{AgOO}^{13} \mathrm{C}^{13} \mathrm{COO}^{-}(\mathrm{m} / \mathrm{z}$ 199). Laboratory frame collision energy $=$ $7 \mathrm{eV}(\mathrm{Ecom}=1.17 \mathrm{eV})$. 
Table 1. Electron affinities and collision-induced dissociation onset energies of relevant metal and non-metals [1, 26-29]

\begin{tabular}{|c|c|c|}
\hline Atom/molecule & $\begin{array}{l}\text { Electron affinity } \\
(\mathrm{eV})\end{array}$ & $\begin{array}{l}\text { Onset energy } \\
(\text { Ecom, eV) }\end{array}$ \\
\hline $\mathrm{Cl}$ & 3.613 & $\mathrm{n} / \mathrm{a}$ \\
\hline $\mathrm{H}$ & 0.754 & No evidence \\
\hline $\mathrm{Li}$ & 0.618 & No evidence \\
\hline $\mathrm{Na}$ & 0.548 & 1.060 \\
\hline $\mathrm{K}$ & 0.501 & 0.480 \\
\hline Cs & 0.471 & No detected fragments \\
\hline $\mathrm{Ag}$ & 1.304 & 0.170 \\
\hline $\mathrm{CO}_{2}$ & $-0.104-0.155$ & $\mathrm{n} / \mathrm{a}$ \\
\hline
\end{tabular}

oxalates make this impossible $\left(\mathrm{CO}_{2}\right.$ has a negative electron affinity, Table 1); the reaction is therefore dependent on the electron affinity of the metal, the size of the metal, and the strength of the bond between the carbon and metal. Table 1 compares a range of metal and non-metal electron affinities with the appearance energy of the metal anions (or not).

As can be seen from the table, silver with the highest electron affinity and largest ion size requires minimal collisional energy to produce the anion. Sodium and potassium produce anions at low eV but hydrogen and lithium do not produce metal anions at all. The cesium oxalate anion produced no fragmentation products. A thorough study of other metal oxalates would provide greater comparisons to determine what interactions are responsible for this phenomenon.

Further to this study and as a follow-up, the authors have been able to transfer the electron from the metal anion to oxygen, suggesting that this method of electrontransfer could result in tailored electron-transfer to biological species, for further analysis.

\section{References}

1. Anderson, T.; Haugen, H. K.; Hotop, H. Binding Energies in Atomic Negative Ions: III. J. Phys. Chem. Ref. Data 1999, 28, 1511-1533.

2. Cavanagh. M. C.; Larsen. R. E.; Schwartz. B. J. Watching Na Atoms Solvate into $(\mathrm{Na}$, e-) Contact Pairs: Untangling the Ultrafast ChargeTransfer-to-Solvent Dynamics of Na- in Tetrahydrofuran (THF). J. Phys. Chem. A 2007, 111, 5144-5157.

3. Glover, W. J.; Larsen, R. E.; Schwartz, B. J. The Roles of Electronic Exchange and Correlation in Charge-Transfer-to-Solvent Dynamics: Many-Electron Nonadiabatic Mixed Quantum/Classical Simulations of Photoexcited Sodium Anions in the Condensed Phase. I. Chem. Phys. 2008, 129, 164505.

4. Grobelny, Z.; Stolarzewicz, A.; Adamus, G.; Buika, G.; Grazulevicius, J. V. Electron-Transfer Processes in the Reaction of $\mathrm{K}-, \mathrm{K}+(15$-crown-
$5)_{2}$ with Carbazole: Unexpected Formation of Metallic Potassium. I. Organometal. Chem. 2000, 595, 66-69.

5. Grobelny, Z.; Stolarzewicz, A.; Maercker, A. Self-Decomposition of K-, $\mathrm{K}+(15 \text {-crown-5 })_{2}$ Tetrahydrofuran Solution Via Organometallic Intermediates. J. Organometal. Chem. 2001, 628, 65-70.

6. Jedlinski, Z. Alkali Metal Supramolecule Complexes and Their Significance in Organic Chemistry. Pure Appl. Chem. 1993, 65, 483-488.

7. Jedlinski, Z.; Misioìek, A.; Growkowski, W.; Janeczek, H.; Wolinska, A. Reactions of Alkali Metal Anions. XV. Reaction of Ketones with Alkali Metal Anions. Tetrahedron 1990, 46, 3547-3558.

8. Larsen, R. E.; Cavanagh, M. C. ; Schwartz, B. J. Searching for Solvent Cavities Via Electron Photodetachment: The Ultrafast Charge-Transferto-Solvent Dynamics of Sodide in a Series of Ether Solvents. J. Chem Phys. 2009, 131, 154506.

9. Montes, L.; Lagowski, J. J. Electrochemical Behavior of Sodium Anions J. Phys. Chem. B 2003, 107, 10665-10670.

10. Middleton, R. A Versatile High Intensity Negative Ion Source. Nucl. Instrum. Methods 1983, 214, 139-150.

11. Middleton, R. Negative Ion Cookbook; University of Pennsylvania Press: Philadelphia, PA, 1989; p. 5.

12. Petrunin, V. V.; Anderson, T.; Balling, P.; Anderson, H. Structural Properties of the Negative Calcium Ion: Binding Energies and FineStructure Splitting. Phys. Rev. Lett. 1996, 76, 744-747.

13. Dollimore, D.; Konieczay, J. L. The Thermal Decomposition of Beryllium Oxalate and Related Materials. Thermochim. Acta 1998, 318, 155163.

14. Greenwood, N. N.; Earshaw, A. Chemistry of the Elements, 2nd ed.; Oxford University Press: Oxford, 1997; p. 1090.

15. Kim, I. H.; Beauchamp, J. L. Cluster Phase Chemistry: Collisions of Vibrationally Excited Cationic Dicarboxylic Acid Clusters with Water Molecules Initiate Dissociation of Cluster Components. J. Phys. Chem. A 2007, 111, 5954-5967.

16. Kim, I. H.; Goddard, A. W.; Beauchamp, J. L. Cluster Phase Chemistry: Gas-Phase Reactions of Anionic Sodium Salts of Dicarboxylic Acid Clusters with Water Molecules. J. Phys. Chem. A 2006, 110, 7777-7786.

17. Kim, I. H.; Johnson, P. V.; Beegle, L. W.; Beauchamp, J. L.; Kanik, I. Electrospray Ionization Ion Mobility Spectrometry of Carboxylate Anions: Ion Mobilities and Mass-Mobility Correlation. J. Phys. Chem. A 2005, 109, 7888-7895

18. Tian, Z.; Chan, B.; Sullivan, M. B.; Radom, L.; Kass, S. R. Lithium Monoxide Anion: A Ground-State Triplet with the Strongest Base to Date. Proc. Nat. Acad Sci. U.S. A. 2008, 105, 7647-7651.

19. Higgins, J.; Zhou, X.; Liu, R.; Huang, T.-S. T. Theoretical Study of Thermal Decomposition Mechanism of Oxalic Acid. J. Phys. Chem. A 1997, 101, 2702-2708.

20. Donia, A. M.; Dollimore, D. Preparation, Identification, and Thermal Investigation of Solid Solutions of Cobalt-Copper Oxalates. Thermochim. Acta 1996, 290, 139-147.

21. Kahwa, I. A.; Mulokozi. A. M. The Thermal Decomposition Temperatures of Ionic Metal Oxalates. J. Therm. Anal. 1981, 22, 61-65.

22. Kutaish, N.; Aggarwal. P.; Dollimore, D. Thermal Analysis of Calcium Oxalate Samples Obtained by Various Preparative Routes. Thermochim. Acta 1997, 297, 131-137.

23. Udupa, M. R. Thermal and Mass Spectral Studies of Urea Oxalic Acid. Thermochim. Acta 1983, 60, 239-241.

24. Boldyrev, V. V. Thermal Decomposition of Silver Oxalate. Thermochim. Acta 2002, 388, 63-90.

25. Martinho, S. J. A.; Beauchamp, J. L. Transition Metal-Hydrogen and Metal-Carbon Bond Strengths: The Keys to Catalysis. Chem. Rev. 1990, 90, 629-688.

26. Gutsev, G. L.; Bartlett, R. J.; Compton, R. N. Electron Affinities of $\mathrm{CO}_{2}$ OCS, and $\mathrm{CS}_{2}$. J. Chem. Phys. 1998, 108, 6756-6762.

27. Quitevis E. L.; Herschbach, D. R. Electron Attachment to $\mathrm{CO}_{2}$ Clusters by Collisional Charge Transfer. J. Phys. Chem. 1989, 93, 1136-1139.

28. Yoshioka, Y.; Schaefer, H. F.; Jordan, K. D. Theoretical Investigation of the Electron Affinity of $\mathrm{CO}_{2}$. J. Chem. Phys. 1981, 75, 1040-1041.

29. Lias, S. G., Liebman, J. F. Ion Energetics Data in NIST Chemistry WebBook, NIST Standard Reference Database Number 69, Lindstrom, P. J.; Mallard, W. G. Eds.; National Institute of Standards and Technology: Gaithersburg MD, 20899, http:/ /webbook.nist.gov, accessed August 6, 2010. 